\title{
The ability of new formamidine sugar-modified derivatives of daunorubicin to stimulate free radical formation in three enzy- matic systems: NADH dehydrogenase, NADPH cytochrome P450 reductase and xanthine oxidase ${ }^{\star}$
}

\author{
Jolanta Pawłowska ${ }^{1}$, Jolanta Tarasiuk ${ }^{1 凶}$, Edward Borowski ${ }^{1}$, Małgorzata Wąsowska ${ }^{2}$, \\ Irena Oszczapowicz ${ }^{2}$ and C. Roland Wolf ${ }^{3}$ \\ ${ }^{1}$ Department of Pharmaceutical Technology and Biochemistry, Technical University of Gdańsk, \\ G. Narutowicza 11/12, 80-952 Gdańsk, Poland; ${ }^{2}$ Institute of Biotechnology and Antibiotics, \\ Warszawa, Starościńska 5, 02-516 Warszawa, Poland; ${ }^{3}$ Molecular Pharmacology Unit, \\ Biomedical Research Centre, Ninewells Hospital and Medical School, Dundee, U.K.
}

Received: 25 October, 1999

Key words: daunorubicin, formamidine derivatives, free radical formation, NADH dehydrogenase, NADPH cytochrome P540 reductase, xanthine oxidase

\begin{abstract}
Some sterically hindered N-substituted derivatives of daunorubicin are known to be poor substrates for NADH dehydrogenase, NADPH cytochrome P450 reductase and xanthine oxidase. In consequence, poor oxygen radical generation by these compounds is observed.

In this study we examined a new family of sugar-N-substituted derivatives of daunorubicin bearing a bulky substituent introduced on the nitrogen atom through the amidine spacer. These compounds were found to be very active in radical formation catalyzed by all three studied enzymes. Thus, the introduction of a heterocyclic ring, even if it is bulky but flexible, on the nitrogen atom of daunosamine moiety through the one-atom spacer (amidine group), does not induce the steric hindrance effect on the interaction of daunorubicin derivatives with these flavoprotein enzymes.
\end{abstract}

The antitumour anthraquinone drugs: daunorubicin and adriamycin (DR and ADR) belong to the most widely used agents in the treatment of a variety of human neoplasms [1, 2].

\footnotetext{
${ }^{\star}$ Presented at the $7^{\text {th }}$ International Symposium on Molecular Aspects of Chemotherapy, September 8-11, 1999, Gdańsk, Poland.

${ }^{凶}$ Correspondence to: J. Tarasiuk.

Abbreviations: ADR, adriamycin; $\mathrm{Me}_{2} \mathrm{SO}$, dimethylsulfoxide; DR, daunorubicin; DR19, $N$-[1-carboethoxy-propen-1-yl]-daunorubicin; 5-NH-DR, 5-imino-daunorubicin; N,N-diBzl-DR, $N, N$-dibenzyl-daunorubicin; 4'-O-glucuronyl-DR, 4'-O-glucuronyl-daunorubicin; 4'-O-THP-ADR, 4'-O-tethrahydropyranyl-adriamycin; 4'-O-THP-DR, 4'-O-tethrahydropyranyl-daunorubicin.
} 
One of the major factors limiting the use of these drugs in anticancer chemotherapy is the development of a dose-dependent cardiotoxicity [3, 4]. Numerous data indicate that cardiac effects of these drugs are the consequence of the mediation by anthraquinone compounds of one-electron transfer from reduced nucleotides to atmospheric oxygen. This process is catalyzed mainly by NADH dehydrogenase [5], NADPH cytochrome P450 reductase [6] and xanthine oxidase [7]. These oxidoreductases catalyze one-electron reduction of anthraquinone compounds and the subsequent nonenzymatic semiquinone anion radical reoxidation by molecular oxygen, generating a cascade of reactive oxygen species ( $\mathrm{O}_{2}^{\circ}, \mathrm{OH}, \mathrm{H}_{2} \mathrm{O}_{2},{ }^{1} \mathrm{O}_{2}$ ), highly toxic for heart cells devoid of antioxidants, due to the peroxidation of cell constituents [8, 9].

The effectivity of anthraquinone compounds in mediating electron transfer from reduced nucleotides to atmospheric oxygen is dependent essentially on their structure, determining the affinity for the three enzymes catalysing this process. The redox properties of anthraquinones play only a secondary role [10].

It is known that the specific antitumour activity of anthraquinone compounds does not correlate with their ability to produce free radicals and, in consequence, with the peroxidation of lipids and other cell constituents [6, $10-13]$. Since different structural factors are responsible for anticancer and oxygen radical generating activities, a suitable modification of anthraquinone compounds could reduce their cardiotoxicity and simultaneously retain their specific antitumour activity. For this reason, the examination of the role of structural factors in the affinity of anthraquinone compounds for oxidoreductases catalysing one-electron transfer has considerable importance.

Up to now, most of the available informations concern the substrate properties of anthraquinone antitumour agents in regard to NADH dehydrogenase [10, 11, 13, 14]. It was evidenced that appropriate modifications of a parent anthraquinone compound could affect its interaction with the enzyme. It was shown that the modification of quinonoid moiety affects the interaction of a compound with $\mathrm{NADH}$ dehydrogenase. 5-Imino-daunorubicin (5-NH-DR) and other 5-iminoderivatives were significantly less effective in stimulating NADH oxidation catalyzed by NADH dehydrogenase in comparison to daunorubicin [11]. Similar results have been obtained for various heterocyclic analogues of anthraquinone. The modification of the quinonoid structure into iminoquinonoid (benzoperimidines, anthrapirydazones) or carboquinonoid (anthrapyridones) groups drastically decreased their interaction with the enzyme, due to the essentially reduced affinity of these compounds for NADH dehydrogenase [13, 15].

In the case of anthracycline antibiotics, the structure of sugar fragment is a very important determinant of their affinity for NADH dehydrogenase. In our previous work we have examined the ability of sugar-modified $(\mathrm{N}$ - and $\mathrm{O}^{\prime}$-substitued) derivatives of anthraquinones to stimulate free radical formation. We have found that $\mathrm{N}$-substitution with bulky moieties introduced on the nitrogen atom (N,N-diBzlDR; DR19, see Abbreviations) resulted in a drastic decrease of substrate properties of sugar-modified derivatives for NADH dehydrogenase, probably due to a steric hindrance effect [10]. Similar effect was observed for $\mathrm{O}^{\prime}$-substitued derivatives of anthracyclines (4'-O-THP-ADR; 4'-O-THP-DR; 4'-O-glucuronyl-DR) [13]. All examined compounds exhibited markedly decreased ability to stimulate free radical production. This demonstrates that, to obtain this effect, the bulky fragment on the sugar moiety should be located not only on the nitrogen but also on the oxygen atoms.

In this study we examined the stimulation of free radical formation by a novel group of formamidine DR derivatives [16], having the bulky substituent (pyrrolidine, morpholine, piperridine or hexamethylenoimine rings) in- 
troduced on the nitrogen atom not directly but through an amidine spacer [17]. The stimulation of free radical formation by these compounds was examined in three enzymatic systems: NADH dehydrogenase, NADPH cytochrome $\mathrm{P} 450$ reductase and xanthine oxidase.

\section{MATERIALS AND METHODS}

Daunorubicin was obtained from Drug Development Branch, National Cancer Institute, Bethesda, MD (U.S.A.). DR19 [16], N,N-diBzlDR [18] and the formamidine derivatives of DR (A, B, C, D) [17] were prepared according to procedures described in the indicated references.

Cytochrome $c$ (type VI from horse heart), $\mathrm{NADH}, \mathrm{NADPH}, \mathrm{NADH}$ dehydrogenase (type I from porcine heart) and xanthine oxidase (grade IV from milk) were obtained from Sigma Chemical Co. (St. Louis, MO, U.S.A.). NADPH cytochrome $\mathrm{P} 450$ reductase (from human liver) was obtained in C. Roland Wolf's laboratory, Ninewells Hospital and Medical School (Dundee, U.K.) according to the procedure described in the indicated references [19, 20].

Cytochrome c acetylation. Cytochrome $c$ $\left(25 \mathrm{mg}\right.$ ) was dissolved at $0^{\circ} \mathrm{C}$ in $1.5-2 \mathrm{ml}$ of a half-saturated solution of sodium acetate. A 10-fold excess of acetic anhydride with respect to lysine groups was added under stirring and the reaction was carried out for $30 \mathrm{~min}$. The reaction mixture was applied on the Sephadex G-25M chromathography column. The acetylated cytochrome $c$ was eluted with $50 \mathrm{mM}$ phosphate buffer, pH 7.4 [21].

Enzymatic studies. Stock solutions of examined compounds $\left(\mathrm{C}_{0}=10^{-3} \mathrm{M}\right)$ were prepared just prior to use. Because of the insolubility of the compound $\mathrm{B}$ in water, it was dissolved in dimethylsulfoxide $\left(\mathrm{Me}_{2} \mathrm{SO}\right)$.

$\mathrm{NAD}(\mathrm{P}) \mathrm{H}$ oxidation was measured at $\lambda=340$ nm using a molar absorption coefficient $\varepsilon=$ $6220 \mathrm{M}^{-1} \mathrm{~cm}^{-1}$ and cytochrome $c$ acetylate re- duction was measured at $\lambda=550 \mathrm{~nm}$ using a coefficient (reduced minus oxidised) equal to $\varepsilon=19600 \mathrm{M}^{-1} \mathrm{~cm}^{-1}$. Absorption measurements were made on a Beckman 3600 spectrophotometer.

\section{RESULTS}

The structures of examined compounds are presented in Fig. 1. N,N-diBzl-DR and DR19 were used as reference compounds [10], and the effect of DR and its sugar-modified derivatives on $\mathrm{NAD}(\mathrm{P}) \mathrm{H}$ oxidation and superoxide production were studied. Experiments were carried out using NADH dehydrogenase, NADPH cytochrome $\mathrm{P} 450$ reductase and xanthine oxidase. The ability of examined compounds to stimulate free radical production was detected as the rate of $\mathrm{NAD}(\mathrm{P}) \mathrm{H}$ oxidation or superoxide production measured by the acetylated cytochrome $c$ reduction method. Results obtained by the two methods were comparable (Table 1).

The derivatives of DR: N,N-diBzl-DR and DR19 unlike DR itself, were noneffective in stimulating $\mathrm{NAD}(\mathrm{P}) \mathrm{H}$ oxidation and superoxide production catalyzed by NADH dehydrogenase and NADPH cytochrome P450 reductase. However, in the xanthine oxidase system, the two DR derivatives showed some activity. Thus, the presence of a steric hindrance had smaller effect on their affinity for xanthine oxidase in comparison with their affinity for the other two enzymes studied.

In contrast, the formamidine derivatives of DR were very active in radical formation catalyzed by all three flavoproteins. These derivatives (A - pyrrolidine ring; $\mathrm{B}$ - morpholine ring; $\mathrm{C}$ - piperridine ring; $\mathrm{D}$ - hexamethylenoimine ring) caused high stimulation of $\mathrm{NAD}(\mathrm{P}) \mathrm{H}$ oxidation and superoxide production. The efficiency of these anthracycline derivatives in stimulating free radical formation was comparable with that of the parent drug DR. 


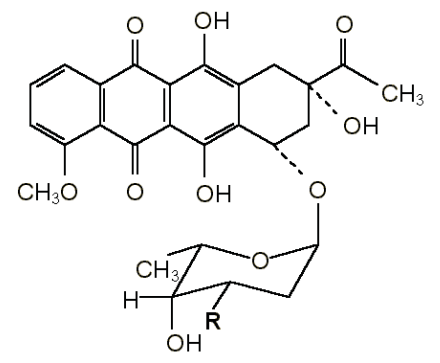

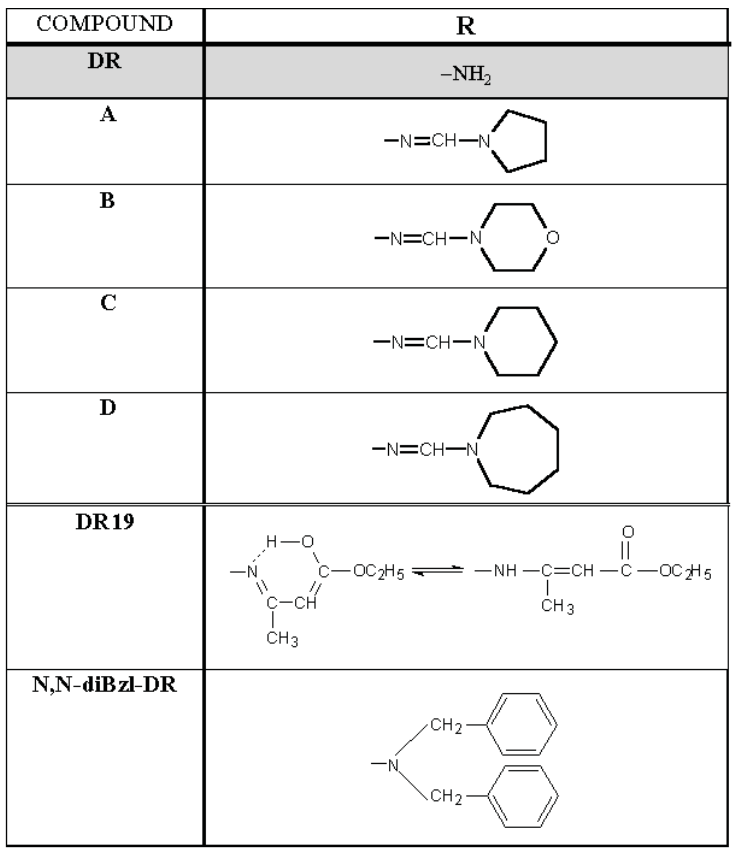

Figure 1. Structures of the examined sugar moiety $\mathrm{N}$-substituted derivatives of daunorubicin (DR).

For the systematic enzyme kinetic studies we have selected two formamidine derivatives of DR: compounds A (with a five-membered ring) and $B$ (with a six-membered ring). DR was used as a reference compound. Since the examined formamidine derivatives exhibited similar behaviour in all three enzymatic systems, further studies were performed in standard NADH dehydrogenase system.

To determine the affinity of examined compounds for NADH dehydrogenase in comparison with that of DR, the kinetic parameters ( $V_{\max }, K_{\mathrm{m}}$ ) were studied (Table 2) using the $\mathrm{NADH}$ oxidation method. The comparison of the $\mathrm{V}_{\text {max }} / K_{\mathrm{m}}$ ratio reflecting the catalytic efficiency and enzyme specificity suggests that the affinity of both compound A and compound $\mathrm{B}$, for $\mathrm{NADH}$ dehydrogenase is similar to the affinity of DR.

\section{DISCUSSION}

It was reported previously that some sugar moiety N-modified derivatives of daunorubicin (N,N-diBzl-DR, DR19) were characterized by diminished efficacy in stimulating free radical production in $\mathrm{NADH}$ dehydrogenase system. We have evidenced that this effect is due to the N-substitution, with bulky moieties resulting in a drastic decrease of substrate properties of the modified derivatives towards NADH dehydrogenase, probably due to a steric hindrance effect [10].

Our previous investigations indicated that an appropriate steric hindrance introduced on the nitrogen atom could be effective in decreasing free radical formation by $\mathrm{NADH}$ dehydrogenase, NADPH cytochrome P450 reductase and xanthine oxidase, however, its effect on xanthine oxidase was the least pronounced. DR19, having the substitution directly on the nitrogen atom, as well as $\mathrm{N}, \mathrm{N}$-diBzl-DR, having rigid bulky moieties substituted through a small spacer, exhibited decreased affinity for the enzymes in all three systems studied.

In this study, we examined a new family of sugar $\mathrm{N}$-substituted derivatives of DR bearing bulky substituents (A - pyrrolidine ring; $\mathrm{B}$ morpholine ring; $\mathrm{C}$ - piperridine ring; $\mathrm{D}-$ hexamethylenoimine ring) introduced on the nitrogen atom not directly but through the amidine spacer. These derivatives were found to be as effective as DR in stimulating free radical formation catalysed by $\mathrm{NADH}$ dehydrogenase, NADPH cytochrome P450 reductase and xanthine oxidase. We observed also that the examined formamidine DR derivatives had good substrate properties $\left(K_{\mathrm{m}}\right)$ with respect to NADH dehydrogenase. 
Table.1. NAD(P)H oxidation and superoxide production by sugar-modified derivatives of daunorubicin (DR) in relation to daunorubicin as a reference compound

\begin{tabular}{|c|c|c|c|c|c|c|}
\hline \multirow{3}{*}{ Compound } & \multicolumn{2}{|c|}{ NADH dehydrogenase } & \multicolumn{2}{|c|}{$\begin{array}{l}\text { NADPH-cytochrome P450 } \\
\text { reductase }\end{array}$} & \multicolumn{2}{|c|}{ Xanthine oxidase } \\
\hline & \multicolumn{2}{|c|}{$0.1-1.0 \mathrm{U} / \mathrm{ml}$} & \multicolumn{2}{|c|}{$0.1-0.6 \mathrm{U} / \mathrm{ml}$} & \multicolumn{2}{|c|}{$0.4 \mathrm{U} / \mathrm{ml}$} \\
\hline & oxidation $^{\mathrm{NADH}}$ & $\begin{array}{c}\mathrm{O}_{2}^{\circ} \\
\operatorname{production}^{\mathrm{b}}\end{array}$ & $\underset{\text { oxidation }^{\mathrm{NADP}}}{\mathrm{NA}}$ & $\begin{array}{c}\mathrm{O}_{2}^{\circ} \\
\text { production }^{\mathrm{b}}\end{array}$ & $\underset{\text { oxidation }^{\mathrm{N}}}{\mathrm{NADH}}$ & $\begin{array}{c}\mathrm{O}_{2}^{\bullet} \\
\operatorname{production}^{\mathrm{b}}\end{array}$ \\
\hline \multirow{2}{*}{ DR } & $\%$ & $\%$ & $\%$ & $\%$ & $\%$ & $\%$ \\
\hline & 100 & 100 & 100 & 100 & 100 & 100 \\
\hline *DR19 & 19.3 & 21.5 & 19.9 & - & 32.3 & 57.7 \\
\hline${ }^{*} \mathbf{N}, \mathbf{N}-d i B z l-D R$ & 0.9 & 1.3 & $<0.1$ & $<0.1$ & - & 18.4 \\
\hline A & 88.0 & - & 77.4 & 90.6 & 79.1 & 99.1 \\
\hline$* \mathbf{B}$ & 76.0 & - & 110.0 & 73.2 & 101.9 & 108.5 \\
\hline $\mathbf{C}$ & 82.1 & - & 83.3 & - & 98.9 & 93.7 \\
\hline D & 102.3 & - & 105.6 & - & - & 92.3 \\
\hline
\end{tabular}

The reaction mixture $(1 \mathrm{ml})$ contained: $0.05 \mathrm{M}$ phosphate buffer, $\mathrm{pH} 7.4,100 \mu \mathrm{M}$ or $* 50 \mu \mathrm{M}$ examined compound, $100 \mu \mathrm{M}$ $\mathrm{NAD}(\mathrm{P}) \mathrm{H}$ and (b) $40 \mu \mathrm{M}$ acetylated cytochrome $c .{ }^{*} 30 \mu \mathrm{l} \mathrm{Me}_{2} \mathrm{SO}$ was added to the reaction mixture; - not measured. The values represent the percentage of the activity measured with daunorubicin (DR) which was taken as $100 \%$. Mean values $( \pm 5 \%)$ of 5-7 determinations are given.

$\mathrm{NAD}(\mathrm{P}) \mathrm{H}$ oxidation and $\mathrm{O} \stackrel{\circ}{\circ}$ production with daunorubicin as substrate were respectively:

NADH dehydrogenase (a) $0.2 \mathrm{U} / \mathrm{ml}$; (b) $0.1 \mathrm{U} / \mathrm{ml}$

a)

$\mathrm{NAD}(\mathrm{P}) \mathrm{H}$ oxidation $(\mu \mathrm{mol} / \mathrm{min})$

DR $(100 \mu \mathrm{M})$

53.4

DR $(50 \mu \mathrm{M})$

NADPH cytochrome $\mathbf{P} 450$ reductase $0.1 \mathrm{U} / \mathrm{ml}$

$\mathrm{DR}(100 \mu \mathrm{M}) \quad 13.5$

$\mathrm{DR}(50 \mu \mathrm{M}) \quad 9.5$

Xanthine oxidase $0.4 \mathrm{U} / \mathrm{ml}$

DR $(100 \mu \mathrm{M})$

13.7

DR $(50 \mu \mathrm{M})$

10.5 b)

$\mathrm{O} \div \frac{\bullet}{2}$ production $(\mu \mathrm{mol} / \mathrm{min})$

54.8

28.8

11.7

9.6

9.3

7.7
In conclusion, our results indicate that $\mathrm{N}$-substitution of DR with bulky rigid moieties even through the small spacer (N,N-diBzl-DR) results in an essential decrease of substrate properties with respect to three enzymes this effect being, however, smaller in the case of xanthine oxidase. The similar effect was observed for compounds containing a steric hindrance which was less pronounced but introduced directly (not through a spacer) on the nitrogen atom (DR19). These modifications of sugar moiety markedly disturbed the interac- tions between DR derivatives and the three oxidoreductases. O'-Substituted anthracycline derivatives (4'-O-THP-ADR; 4'-O-THP-DR; 4'-O-glukuronyl-DR) [13] exhibited similar effect. The direct introduction on the oxygen atom of sugar moiety of the bulky, nonaromatic, non-rigid substituent decreased the ability of the derivative formed to stimulate free radical formation.

In contrast, the introduction on the nitrogen atom, through the one-atom spacer, of daunosamine moiety of a five or six membered 
Table 2. Kinetic parameters for daunorubicin (DR) and new sugar N-substituted derivatives of DR

\begin{tabular}{llcc}
\hline \multirow{2}{*}{ Compound } & \multicolumn{3}{c}{ NADH dehydrogenase $(0.2 \mathrm{U} / \mathrm{ml})$} \\
\cline { 2 - 4 } & $\boldsymbol{K}_{\mathbf{m}}$ & $\boldsymbol{V}_{\max }$ & $\boldsymbol{V}_{\max }$ \\
& {$[\mu \mathrm{M}]$} & {$[\mu \mathrm{mol} / \mathrm{min}]$} & $\boldsymbol{K}_{\max }$ \\
DR & $57.2 \pm 14.4$ & $81.4 \pm 14.3$ & $1.4 \pm 0.6$ \\
A & $49.7 \pm 4.3$ & $55.8 \pm 7.1$ & $1.1 \pm 0.2$ \\
${ }^{*}$ B & $43.0 \pm 10.7$ & $47.7 \pm 7.6$ & $1.1 \pm 0.5$ \\
\hline
\end{tabular}

The reaction mixture $(1 \mathrm{ml})$ contained: $0.05 \mathrm{M}$ phosphate buffer, $\mathrm{pH} 7.4,0-100 \mu \mathrm{M}$ or $(*)$ 0-50 $\mu \mathrm{M}$ examined compound, $100 \mu \mathrm{M}$ NADH. $\left(^{*}\right) 30 \mu \mathrm{l}$ of $\mathrm{Me}_{2} \mathrm{SO}$ was added to the reaction mixture. The results are expressed as the mean values \pm S.D. of $3-5$ determinations.

heterocyclic flexible ring, did not induce the steric hindrance effect in the interaction of the $\mathrm{DR}$ derivative with NADH dehydrogenase, $\mathrm{NADPH}$ cytochrome $\mathrm{P} 450$ reductase or xanthine oxidase.

\section{R E F E R E N C E S}

1. Abdella, B.R.J. \& Fisher, J. (1985) A chemical perspective on the anthracycline antitumor antibiotics. Environ. Health Perspect. 64, $3-18$.

2. Lown, J.W. (1993) Discovery and development of anthracycline antitumor antibiotics. Chem. Soc. Rev. 165-176.

3. Olson, R.D. \& Mushlin, P.S. (1990) Doxorubicin cardiotoxicity: Analysis of prevailing hypothesis. J. FASEB 4, 3076-3086.

4. Havlin, K.A. (1992) Cardiotoxicity of anthracyclines and other antineoplastic agents. Cardiovascular Toxicology; 2nd edn. (Acosta, D., ed.) pp. 143-164, Raven Press Ltd., New York.

5. Davies, K.J.A. \& Doroshow, J.H. (1986) Redox cycling of anthracyclines by cardiac mitochondria. I. Anthracycline radical formation by NADH dehydrogenase. J. Biol. Chem. 261, 3060-3067.

6. Kharasch, E.D. \& Novak, R.F. (1983) Bis (alkylamino) anthracenedione antineoplastic agent metabolic activation by NADPH-cyto- chrome P-450 reductase and NADH dehydrogenase: Diminished activity relative to anthracyclines. Arch. Biochem. Biophys. 224, 682-694.

7. Pan, S.S. \& Bachur, N.R. (1980) Xanthine oxidase catalysed reductive cleavage of anthracycline antibiotics and free radical formation. Mol. Pharmacol. 17, 95-99.

8. Doroshow, J.H. (1983) Effect of anthracycline antibiotics on oxygen radical formation in rat heart. Cancer Res. 43, 460-472.

9. Powis, G. (1989) Free radical formation by antitumour quinones. Free Radical Biol. Med. 6, 63-101.

10. Tarasiuk, J., Garnier-Suillerot, A., Stefańska, B. \& Borowski, E. (1992) The essential role of anthraquinones as substrates for $\mathrm{NADH}$ dehydrogenase in their redox cycling activity. Anti-Cancer Drug Design 7, 329-340.

11. Tarasiuk, J., Stefańska, B. \& Borowski, E. (1990) Low stimulation of NADH oxidation and oxygen consumption by 5-iminodaunorubicin and its derivatives. Acta Biochim. Polon. 37, 251-259.

12. Frank, P. \& Novak, R.F. (1986) Effects of anthrapyrazole antineoplastic agents on lipid peroxidation. Biochem. Biophys. Res. Commun. 140, 797-807.

13. Tarasiuk, J., Tkaczyk-Gobis, K., Stefańska, B., Dzieduszycka, M., Priebe, W., Martelli, S. \& 
Borowski, E. (1998) The role of structural factors of anthraquinone compounds and their quinone-modified analogues in NADH dehydrogenase - catalysed oxygen radical formation. Anti-Cancer Drug Design 13, 923-939.

14. Tarasiuk, J., Pawłowska, J., Dzieduszycka, M., Wolf, C.R., Priebe, W. \& Borowski, E. (1997) The role of structural factors of antitumor anthraquinones and their analogs in the mediation of one-electron transfer catalysed by xanthine oxidase and NADPH-cytochrome P450-reductase. 6th International Symposium on Molecular Aspects of Chemotherapy, Gdansk 9-12 VII 1997, Abstract Book, 96.

15. Stefańska, B., Dzieduszycka, M., Martelli, S., Tarasiuk, J., Bontemps-Gracz, M. \& Borowski, E. (1993) 6-[(Aminoalkyl)amino]-substituted $7 H$-benzo[ $e$ ]perimidin-7-ones as novel antineoplastic agents. Synthesis and biological evaluation. J. Med. Chem. 36, 38-41.

16. Stefańska, B., Borowski, E., Falkowski, L. \& Martelli, S. (1986) Synthesis and antileukemic activity of some novel N-substituted derivatives of daunorubicin. Polish J. Chem. 60, 525-529.

17. Oszczapowicz, I., Grodner, J., Radzikowski, C., Kuśnierczyk, H. \& Opolski, A. (1997). Polish patent application - P 322756.
18. Tong, G.L., Wu, H.Y., Smith, T.H. \& Henry, D.W. (1979) Adriamycin analogues. 3. Synthesis of N-alkylated anthracyclines with enhanced activity and reduced cardiotoxicity. $J$. Med. Chem. 22, 912-918.

19. Yasukochi, Y. \& Masters, B.S.S. (1976) Some properties of a detergent solubilized NADPH cytochrome (cytochrome P450) reductase purified by biospecific affinity chromathography. J. Biol. Chem. 251, 5337-5344.

20.Wolf, C.R., Lewis, A.D., Carmichael, J., Ansell, J., Adams, D.J., Hickson, I.D., Harris, A., Balkwill, F.R., Griffin, D.B. \& Hayes, J.D. (1987) Glutathione S-transferase expression in normal and tumor cells resistant to cytotoxic drugs; in Glutathione S-transferase and Carcinogenesis (Mantle, T.J., Pickett, C.B., Hayes, J. D., eds.) pp. 199-212, Taylor \& Francis, London.

21. Azzi, A., Montecucco, C. \& Richter, C. (1975) The use of acetylated ferricytochrome $c$ for the detection of superoxide radicals produced in biological membranes. Biochem. Biophys. Res. Commun. 65, 597-603. 